ECCOMAS

Proceedia
COMPDYN 2019

$7^{\text {th }}$ ECCOMAS Thematic Conference on Computational Methods in Structural Dynamics and Earthquake Engineering M. Papadrakakis, M. Fragiadakis (eds.) Crete, Greece, 24-26 June 2019

\title{
SEISMIC ASSESSMENT OF MASONRY AGGREGATES: A NURBS- BASED LIMIT ANALYSIS COMPUTATIONAL TOOL
}

\author{
Nicola Grillanda ${ }^{1}$, Andrea Chiozzi ${ }^{2}$, Gabriele Milani $^{1}$ and Antonio Tralli ${ }^{2}$ \\ ${ }^{1}$ Department of Architecture, Built Environment and Construction Engineering (A.B.C.), Technical \\ University of Milan \\ Piazza Leonardo da Vinci, 32, 20133 Milan, Italy \\ nicola.grillanda@polimi.it, gabriele.milani@polimi.it \\ ${ }^{2}$ Department of Engineering, University of Ferrara \\ Via Saragat 1, 44122 Ferrara, Italy \\ andrea.chiozzi@unife.it, tra@unife.it
}

\begin{abstract}
Masonry structures represent one of the most common worldwide structural typologies for buildings. To date, many historical towns and villages in Italy are built from aggregates of masonry buildings, in which each architectural unit interacts with others forming a complex structural system. Local failure mechanisms are particularly important for the assessment of the safety level of masonry buildings and, especially, of aggregates: recent seismic events have provided evidence that masonry buildings are particularly vulnerable to out-of-plane actions, triggering a wide number of local collapse mechanisms. For this reason, this contribution proposes a new fast computational tool for the automated seismic assessment of local failure mechanisms in masonry aggregates through limit analysis. The proposed tool is based on the NURBS geometric description of the aggregate, which is the common output of many free form modelers. This peculiarity makes the tool easily interfaced with CAD design environments and requires no advanced computational skills to the user. The historical center of Arsita (Italy), a beautiful example of masonry aggregate, which was hit by the 2009 L'Aquila earthquake, is analyzed as a case study and the results are used to validate the proposed tool.
\end{abstract}

Keywords: Masonry aggregates, NURBS, Limit analysis.

ISSN:2623-3347 (C) 2019 The Authors. Published by Eccomas Proceedia Peer-review under responsibility of the organizing committee of COMPDYN 2019. doi: 10.7712/120119.7008.19298 


\section{INTRODUCTION}

Masonry constructions are the most widespread structures in the Italian historical centers, which are often the result of an uncontrolled urban development based on buildings erected in continuity to each other, so resulting in aggregates of constructions. These were generated by the progressive transformation of the urban tissue, in which elevation floors were added to existing constructions and adding structural units made plan extensions to the existing ones. As a result, it is very difficult both to distinct the structurally independent units and to identify the global response of the building aggregates. Therefore, seismic vulnerability assessment of masonry aggregates in the Italian historical centers represents a specific and very actual problem [1].

The main difficulties of this task are related to the low knowledge level of the structures, which were in many cases built in absence of anti-seismic design regulations, particularly due to the absence of drawings or reports. In addition, even if in most practical cases, and as allowed by the Italian building codes [2,3], the safety assessment would mainly regard a single building within an aggregate, the analysis of these complex constructions should require the complete modeling of all structural units. The seismic response of masonry building included in aggregates is influenced by several aspects, such as the topography and morphology of the foundation soil, the plan configuration of the aggregate, the degree of connection between adjacent buildings, building position within the aggregate, homogeneity of structural characteristics and, finally, masonry textures (which can be strongly irregular in case of aggregates [4]). A rigorous approach would require a detailed analysis of the entire aggregate, but because of the inherent complexity of the aggregate itself, some approximations need to be introduced. Simplified methods based on parametric analyses on large scale have been recently proposed [5-7].

Recent seismic events have provided evidence of the high vulnerability of these structures to out-of-plane actions, triggering a wide number of local collapse mechanisms [8-12]. Therefore, local analyses are particularly important for the assessment of the safety level of historical masonry buildings [13,14] and, therefore, aggregates. Local failure mechanisms can be evaluated in simply way through limit analysis techniques by adopting the assumptions proposed by Heyman for masonry material, i.e. null value of ultimate tensile stress, infinite compressive strength and exclusion of sliding between blocks [15]. However, it is worth mentioning the tensile strength is not always exactly null, but quite variable and uncertain. In addition, the resistance to compression is at least an order of magnitude greater but finite, as well as the shear resistance, especially in absence of meaningful normal compression, may result quite low. The adoption of an isotropic no-tension material could result too simplistic and suitable homogenization techniques should be preferred [16-19].

In this paper, a new fast computational tool for the automated seismic assessment of local failure mechanisms in masonry aggregates through NURBS-based limit analysis [20] is proposed. According to this procedure, a given masonry structure can be modeled as a coarse rigid block assembly, where dissipation is allowed only along element edges. NURBS (NonRational Uniform B-Spline) [21] are special approximating basis functions widely used in the field of 3D modeling for their ability to approximate the geometry of curved elements (i.e. arches, vaults or walls with circular holes) in an extremely accurate way. Starting from the obtained rigid bodies assembly, an upper bound limit analysis problem with very few optimization variables can be devised. The main aspects of masonry material are taken into account through a homogenization approach based on a Method of Cells-type approach [18]. Due to the very limited number of rigid elements used, the quality of the computed failure mechanism depends on the shape and position of the interfaces, where dissipation is allowed. Mesh 
adjustments are therefore needed: a meta-heuristic algorithm (e.g. genetic algorithm) is thus implemented in order to modify the mesh and find the minimum kinematic load multiplier (i.e. the collapse multiplier). It should be noted that this is the natural evolution of the previously published [22] open-source code ArchNURBS. Recent applications of this method can be found in the literature [23-30].

The historical center of Arsita (Italy), which was hit by the 2009 L'Aquila earthquake [31] and subsequently involved in the reconstruction plan performed by ENEA (Italian National Agency for New Technologies, Energy and Sustainable Economic Development) [32,33], is analyzed as a case study. In particular, the analysis of the masonry aggregate named "Il Torrione" is presented.

\section{NURBS LIMIT ANALYSIS}

In this section, we present the NURBS-based limit analysis procedure.

The analysis of the aggregate starts with a NURBS representation of the geometry. The main advantage of NURBS is the wide range of geometries that can be represented with accuracy through very few elements. Another point is that NURBS entities can be directly interfaced with commercial CAD packages, such as Rhinoceros ${ }^{\circledR}$ [34]. NURBS basis functions are built on B-splines basis functions, which are piecewise polynomial functions defined by "knots" (i.e. points in a parametric domain) $\Xi=\left\{\xi_{1}, \xi_{2}, \ldots, \xi_{n+p+1}\right\}$, where $p$ and $n$ denote the polynomial order and the total number of basis functions, respectively. Given a set of weights $w_{i} \in \mathbb{R}$ and the $i$-th B-spline basis function $\left(N_{i, p}\right)$, then the NURBS basis function $R_{i, p}$ can be written as follows:

$R_{i, p}(\xi)=\frac{N_{i, p}(\xi) w_{i}}{\sum_{i=1}^{n} N_{i, p}(\xi) w_{i}}$

A NURBS surface of degree $p$ in the u-direction and $q$ in the v-direction is a parametric surface in the three-dimensional Euclidean space defined as:

$\mathbf{S}(u, v)=\sum_{i=0}^{n} \sum_{j=0}^{m} R_{i, j}(u, v) \mathbf{B}_{i, j}$

where $\left\{\mathbf{B}_{i j}\right\}$ form a bidirectional net of control points. A set of weights $\left\{w_{i, j}\right\}$ and two separate knot vectors in both $u$ and $v$ directions must be defined.

In the numerical simulations presented in this work, geometries are modeled within Rhinoceros as NURBS surfaces. This model is imported within a MATLAB® environment, in which thickness and offset properties are assigned to each surface, through the IGES (Initial Graphics Exchange Specification) standard [35]. At this point, NURBS properties may be manipulated to define a NURBS mesh of the masonry mid-surface, in which each element is a NURBS surface itself (see Figure 1).

Starting from the geometrical properties of each element, an upper bound formulation can be obtained and implemented through an efficient internal point linear programming algorithm, e.g. using open programming codes as MATLAB, in order to assess the ultimate load bearing capacity of a given masonry structure. Given an initial NURBS mesh, each element is considered as a rigid body and his kinematics is thus determined by the six generalized velocity components $\left\{u_{x}^{i}, u_{y}^{i}, u_{z}^{i}, \Phi_{x}^{i}, \Phi_{y}^{i}, \Phi_{z}^{i}\right\}$ of his center of mass, expresses in a global reference system $O x y z$. On the structure, dead loads $\mathbf{F}_{0}$ and live loads $\Gamma$ are acting. Possible dissipation is allowed only along element interfaces. In order to enforce closely compatibility along inter- 
faces and correctly evaluate the possible dissipated power, integrals are numerically evaluated on interfaces by means of classic collocation method on several points $P_{i}$. On each point $P_{i}$, a local reference system $(\mathbf{n}, \mathbf{s}, \mathbf{t})$ is defined, where $\mathbf{n}$ is the unit vector normal to the interface, $\mathbf{s}$ is the tangential unit vector in the longitudinal direction and $\mathbf{t}$ is the tangential unit vector in the transversal direction, as sketched in Figure 2(a).

In the evaluation of the dissipated power, a rigid plastic behavior has been assigned to masonry material. In order to reproduce all the main aspects of masonry in aggregate buildings in a simple way, such as no-tension material properties with finite values of compressive strength, presence of different and irregular masonry textures for each structural units and disintegration failure modes, the use of homogenization techniques is recommended [17-19]. Therefore, in this work a homogenized three-dimensional failure surface has been adopted, which includes, as it can be seen in Figure 2(b-c), a very low value of tensile strength (eventually null), a Mohr-Coulomb behavior in shear and a linear cap in compression.

The obtained linear programming problem is reported in Eq. 3, in which geometric constraints (a), compatibility constraints (b), non-negativity of plastic multipliers (c) and normalization of the power dissipated by live loads (d) are included.

$\left\{\begin{array}{l}\mathbf{A}^{e q} \mathbf{u}=\mathbf{0} \\ \Delta \tilde{\mathbf{u}}=\dot{\lambda}^{T} \frac{\partial f}{\partial \dot{\boldsymbol{\sigma}}} \\ \dot{\lambda} \geq 0 \\ P_{\Gamma=1}=1 \\ \min \left\{\Gamma=\frac{P_{i n}-\mathbf{F}_{0}^{T} \mathbf{u}}{P_{\Gamma=1}}\right\}\end{array}\right.$

For all cases in which the collapse mechanism may be complex, such as curved elements or walls constrained at the edges in which the failure does not take place by a simple overturning, the initial mesh has to be modified. In other words, the optimal position of the fracture lines needs to be found in order to avoid an excessive overestimation of the load multiplier. In these cases, a progressive adaptation of the mesh is performed through a Genetic Algorithm, which applies some modifications to the subdivision of NURBS surfaces optimizing, iteration after iterations, the kinematic multiplier.

The reader is referred to [20,24,25] for further details about the NURBS-based upper bound limit analysis procedure.

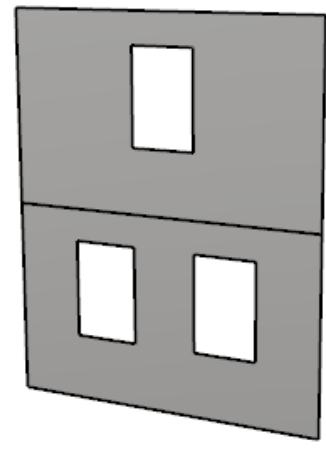

(a)

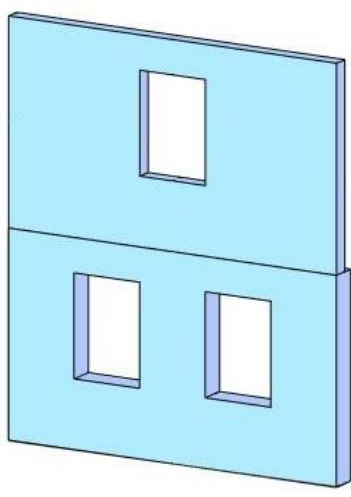

(b)

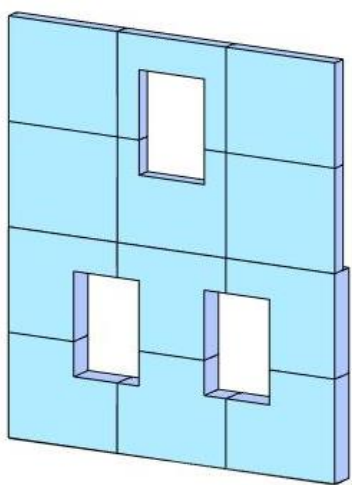

(c)

Figure 1. Passage to the initial NURBS surfaces in CAD environment (Rhinoceros®) to the initial mesh of the NURBS model in MATLAB®. 


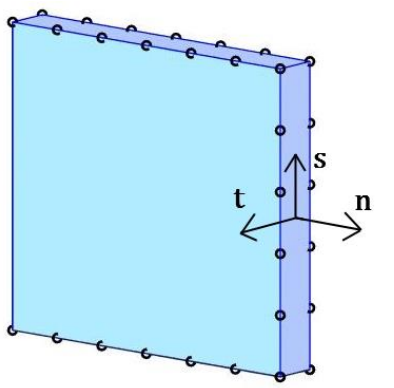

(a)

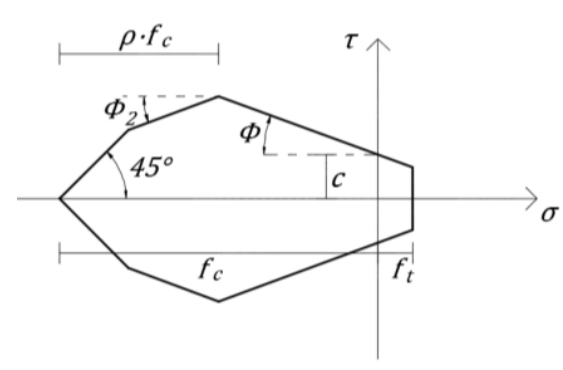

(b)

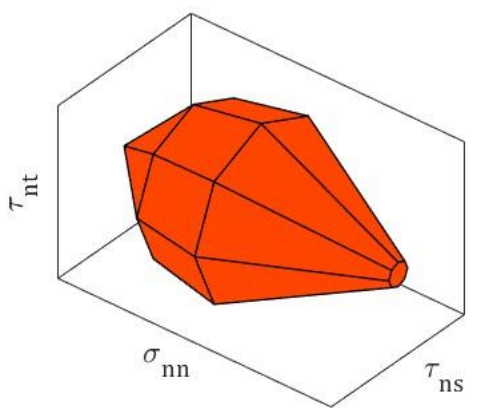

(c)

Figure 2. (a) NURBS element and local reference system at the interface and (b-c) assigned failure surface ((b) 2D section and (c) 3D linearized surface).

\section{NUMERICAL SIMULATIONS: THE CASE OF ARSITA}

Arsita is a town located in the district of Teramo (Abruzzo Region), near the Gran Sasso Massif. The small and nice historic center, which includes a total amount of 17 masonry aggregates, presents very inhomogeneous built up with regard to earthquake damages, vulnerability, past interventions, maintenance and marks of past seismic events. Although the intensity of L'Aquila 2009 earthquake may be considered moderate, the combination of several factors (mainly high potential vulnerability, particular topographic and soil conditions) led to a non negligible widespread damage [31].

The masonry aggregate named "Il Torrione", which is the $8^{\text {th }}$ aggregate among the 17 according to the classification provided by ENEA [32], has been chosen as meaningful case study for the presented work. This aggregate is characterized by an irregular horizontal plane, foundations at different levels and three floors (roofing included). Four different structural units have been identified. Structural units and a series of horizontal sections are depicted respectively in Figure 3 and Figure 4. According to the documents provided by ENEA [32,33], all the several typologies of horizontal floors are characterized by the absence of chains and concrete edgings; moreover, roofs do not apply horizontal thrusts on the perimeter walls. The floor frame directions, which has been hypothesized by ENEA's documents, is depicted in Figure 4, whereas in Table 1 weight and variable loads associated with each horizontal floor are reported. In Table 1 also seismic load combinations provided by [2] are shown.

The masonry aggregate has been analyzed by means of a procedure of linear kinematic analysis provided by the Italian code for existing masonry construction [2,3]: for each rigid block included in the model, a horizontal loads configurations, which is proportional to the supported weights, is applied in addition to vertical loads. The horizontal multiplier $\alpha_{0}$, which is the horizontal load multiplier associated with the activation of the local failure mechanism, is evaluated by means of Principle of Virtual Work.

The NURBS-based limit analysis has been applied in order to perform the evaluation of the horizontal multiplier automatically for each structural unit. Material parameters of masonry material, associated with the homogenized failure surfaces depicted in Figure 2(b), are reported in Table 2. An appropriate nomenclature has been assigned to each wall (see Figure 5) in order to show the several failure mechanisms in an orderly way. Results obtained are reported from Figure 6 to Figure 10. In some cases, different hypotheses have been adopted for the quality of connection between orthogonal walls (see for example Figure 8 and Figure 10). Finally, the results of the analysis on the whole façade on the west side of the building (walls C1-D1 according to Figure 5) is presented in Figure 11. In this case, both the hypotheses of multi-leaf wall and compact wall between the two structural units have been taken into account: as result, a lower horizontal multiplier has been found in case of multi-leaf wall. 


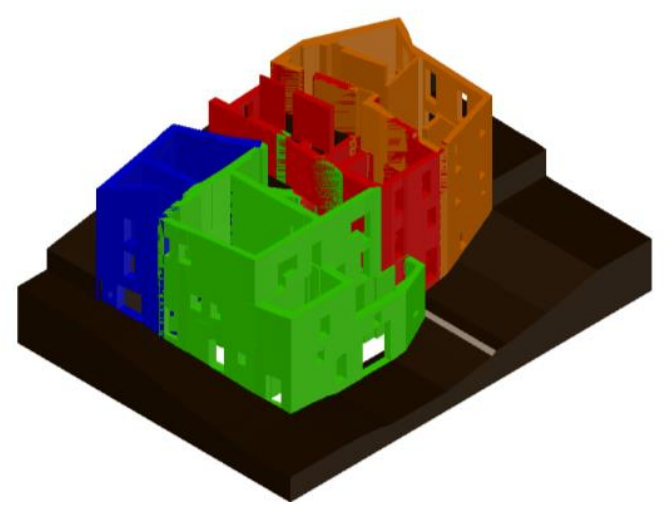

(a)

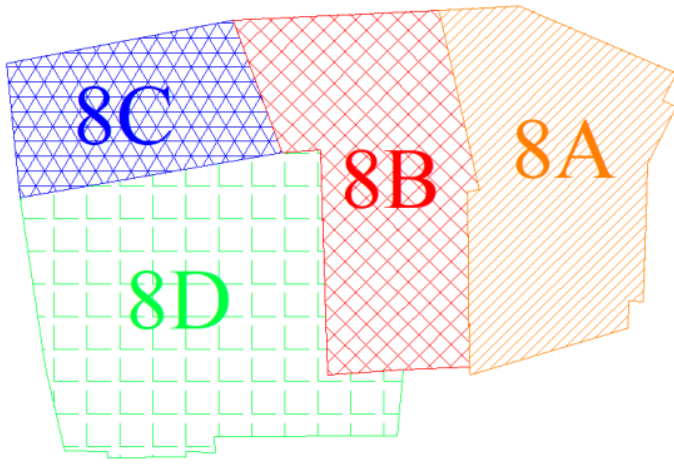

(b)

Figure 3. Aggregate "Il Torrione" of Arsita: (a) 3D CAD model and (b) subdivision in structural units in plan view.

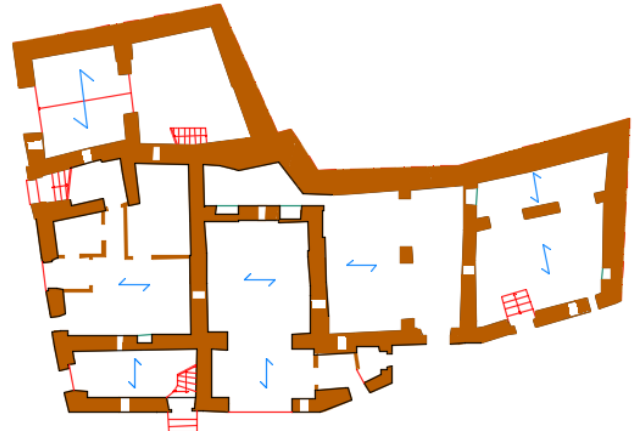

(a) Ground floor

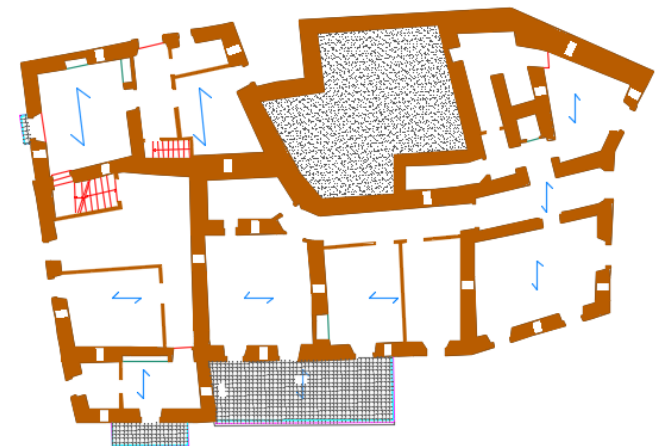

(c) First floor

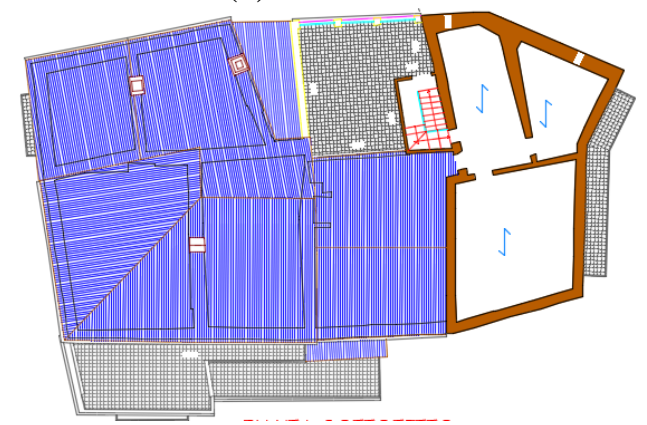

(e) Loft floor

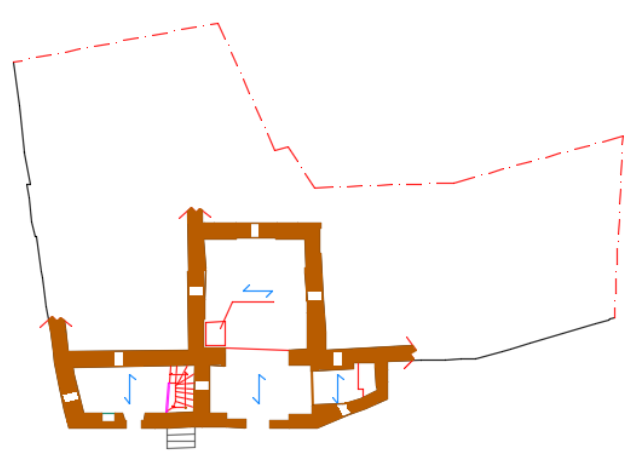

(b) Mezzanine over the ground floor

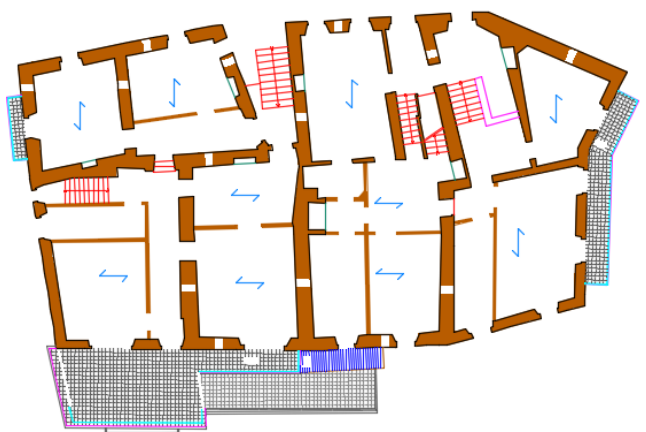

(d) Second floor

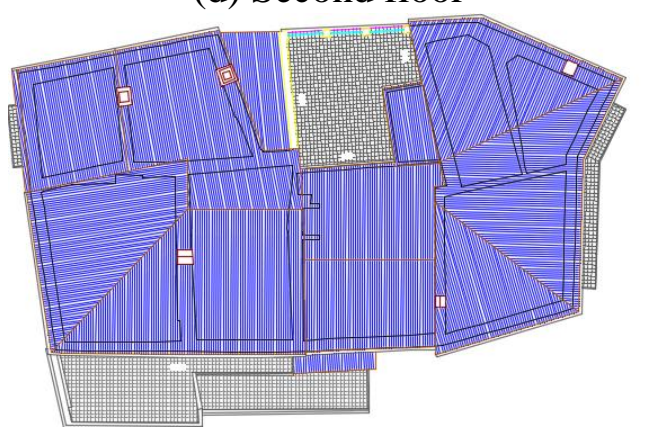

(f) Roofing floor

Figure 4. Plane sections and floor frame directions. 

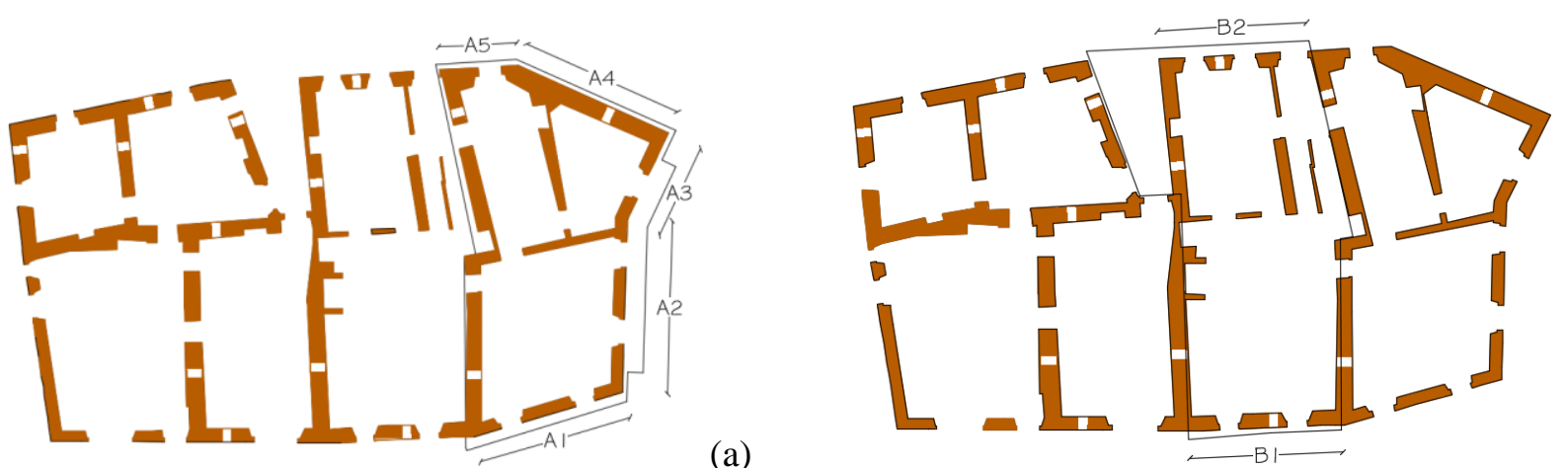

(a)

(b)
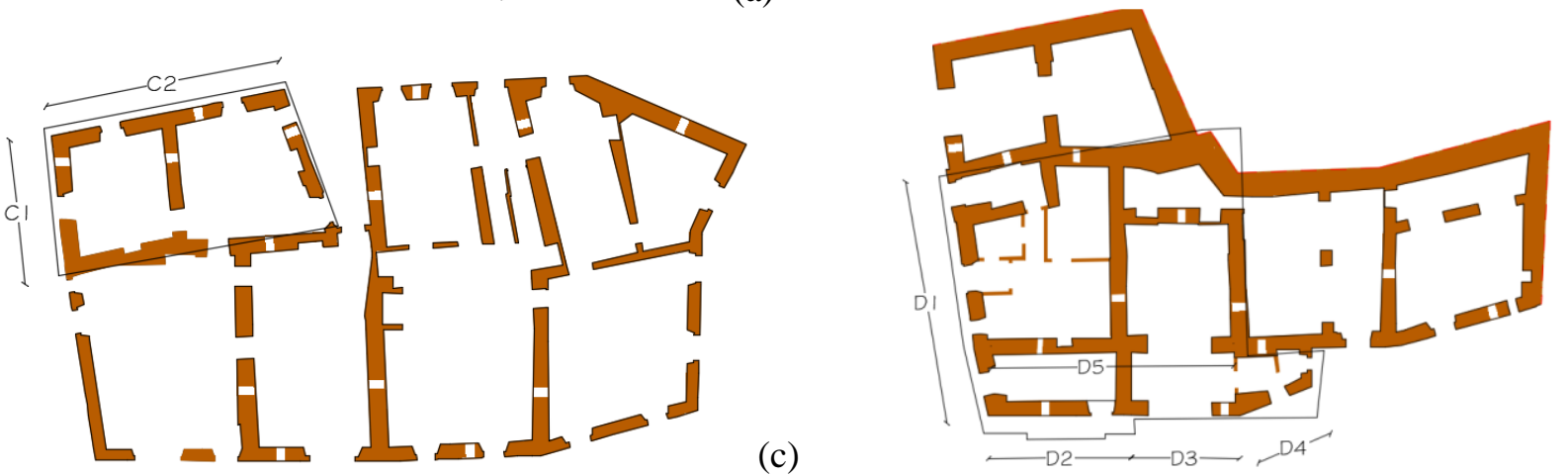

(d)

Figure 5. Nomenclature adopted for walls of each structural unit: (a) A, (b) B, (c) C and (d) D.

\begin{tabular}{|c|c|c|c|c|c|}
\hline $\begin{array}{c}\text { Structural } \\
\text { unit }\end{array}$ & $\begin{array}{l}\text { Floor (thickness } \\
[\mathrm{cm}])\end{array}$ & $\begin{array}{c}\text { Self-weight } \\
(\mathbf{G}) \\
{\left[\mathbf{k N} / \mathbf{m}^{2}\right]}\end{array}$ & $\begin{array}{l}\text { Variable } \\
\operatorname{load}(\mathbf{Q}) \\
{\left[\mathrm{kN} / \mathrm{m}^{2}\right]}\end{array}$ & $\begin{array}{c}\text { Seismic } \\
\text { combination } \\
\text { coefficient } \\
\left(\psi_{2 \mathrm{j}}\right)\end{array}$ & $\begin{array}{c}\text { Seismic } \\
\text { combination } \\
\left(\mathrm{G}+\psi_{2 \mathrm{j}}{ }^{\circ} \mathbf{Q}\right) \\
{\left[\mathrm{kN} / \mathrm{m}^{2}\right]}\end{array}$ \\
\hline \multirow{6}{*}{$\mathrm{A}, \mathrm{B}, \mathrm{C}$} & First $(20+5)$ & 3.45 & 2 & 0.3 & 4.05 \\
\hline & Second $(24+4)$ & 3.65 & 2 & 0.3 & 4.25 \\
\hline & Loft (18) & 3 & 2 & 0.3 & 3.6 \\
\hline & Roofing & 1 & - & 0 & 1 \\
\hline & First balcony (25) & 6 & 4 & 0.6 & 8.4 \\
\hline & Second balcony (17) & 4.1 & 4 & 0.6 & 6.5 \\
\hline \multirow{6}{*}{$\mathrm{D}$} & First & 6 & 2 & 0.3 & 6.6 \\
\hline & Second & 4 & 2 & 0.3 & 4.6 \\
\hline & Loft (18) & 3 & 2 & 0.3 & 3.6 \\
\hline & Roofing & 1 & - & 0 & 1 \\
\hline & First balcony (25) & 6 & 4 & 0.6 & 8.4 \\
\hline & Second balcony (17) & 4.1 & 4 & 0.6 & 6.5 \\
\hline
\end{tabular}

Table 1. Floor loads and seismic combinations (according to the Italian building code [2]).

\begin{tabular}{lccc}
\hline Property & Symbol & Value & Unit of measure \\
\hline Specific weight & $\gamma$ & 18 & $\mathrm{kN} / \mathrm{m}^{3}$ \\
Ultimate tensile strength & $\mathrm{f}_{\mathrm{t}}$ & 0.01 & $\mathrm{MPa}$ \\
Ultimate compressive strength & $\mathrm{f}_{\mathrm{c}}$ & 2.4 & $\mathrm{MPa}$ \\
Cohesion & $\mathrm{c}$ & 0.01 & $\mathrm{MPa}$ \\
Friction angle & $\Phi$ & 37 & $\circ$ \\
Linear cap in compression & $\rho$ & 0.5 & - \\
& $\Phi_{2}$ & 10 & $\circ$ \\
\hline
\end{tabular}

Table 2. Mechanical properties adopted for masonry. 

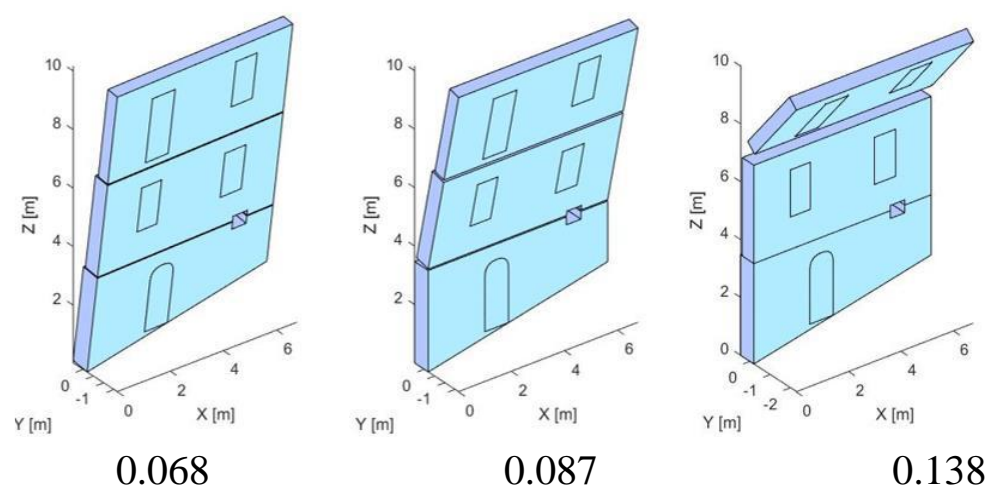

(a)

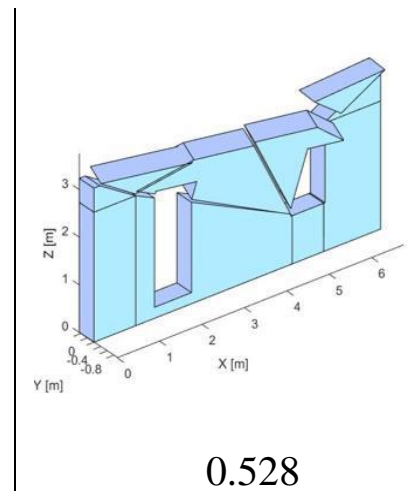

(b)

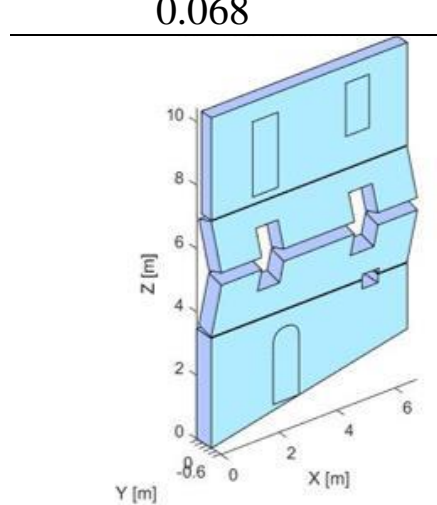

2.604
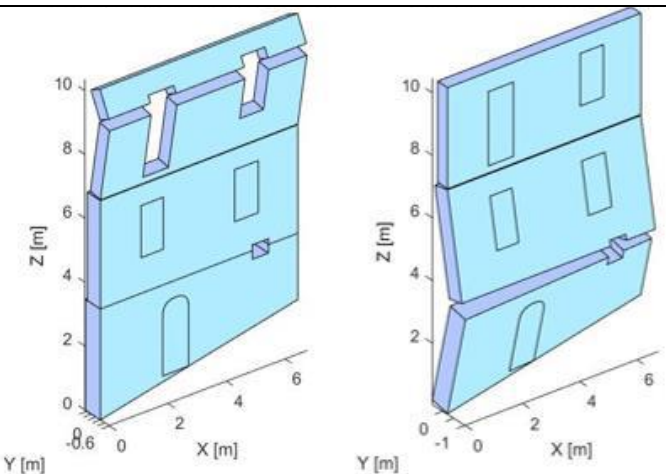

1.081

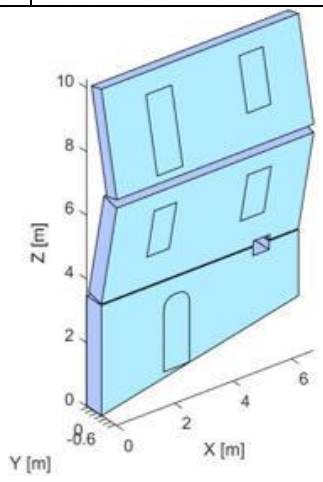

(c)

Figure 6. Wall A1, local failure mechanisms and horizontal load multipliers $\alpha_{0}$ : (a) overturning, (b) horizontal flexure at the top and (c) vertical flexure.
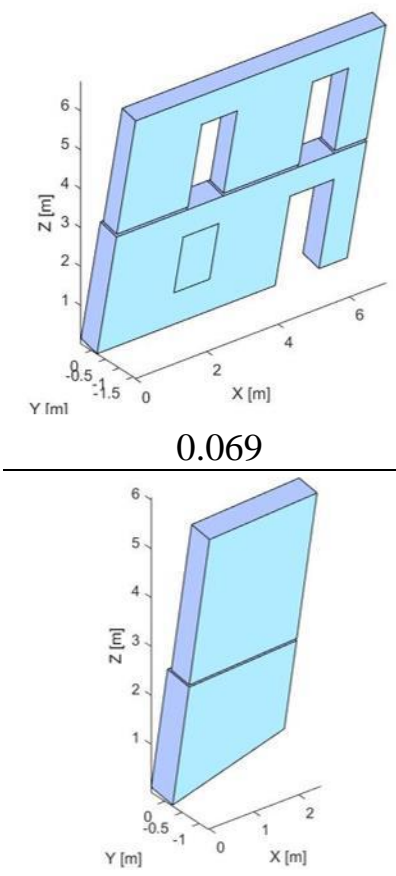

0.097

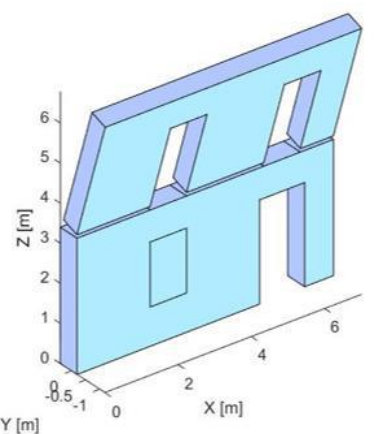

(a)

0.127

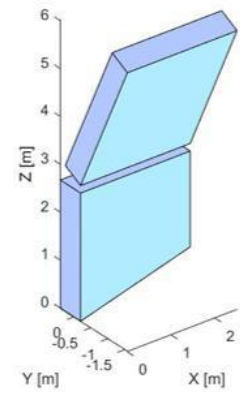

0.141

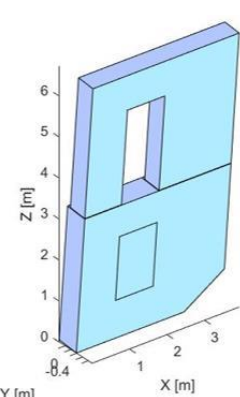

0.058

0.058

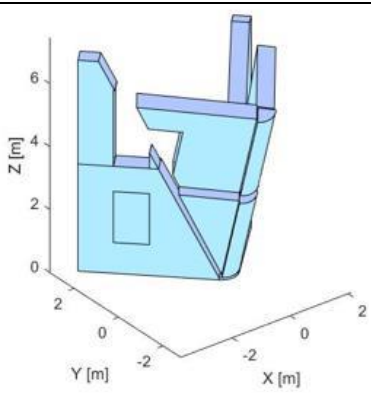

(d)

Figure 7. Walls A2-4, local failure mechanisms and horizontal load multipliers $\alpha_{0}$ : overturning of (a) wall A1, (b) wall A2, (c) wall A3 and (d) corner overturning of walls A3-4. 


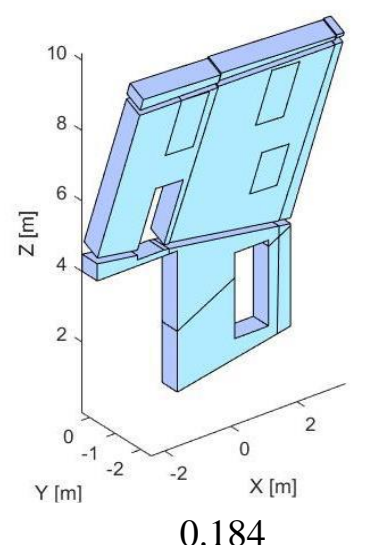

(a)

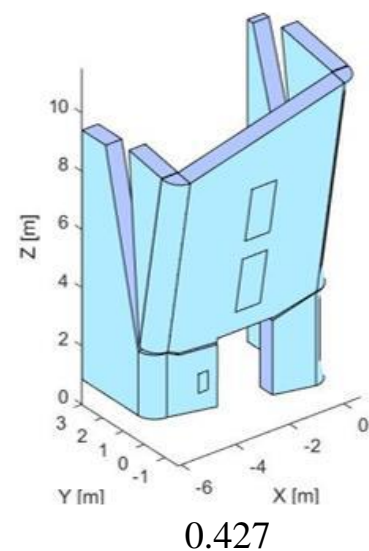

(b)
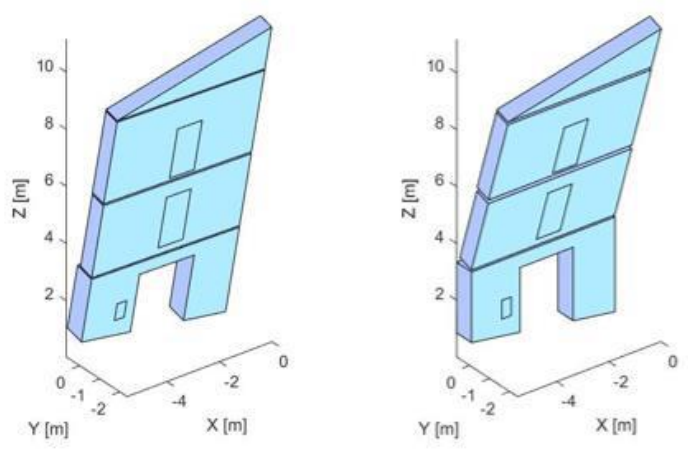

0.069

0.095
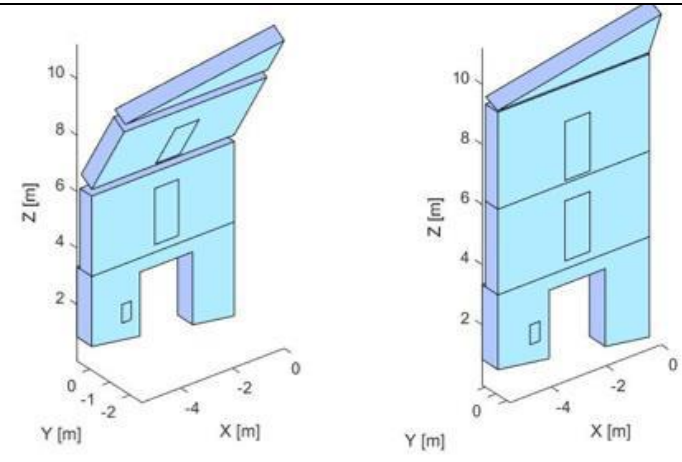

0.160

0.873

(c)

Figure 8. (a) Wall B1 and (b-c) Wall C1, local failure mechanisms and horizontal load multipliers $\alpha_{0}$ : overturning with (b) good and (c) low quality of connection with orthogonal walls.
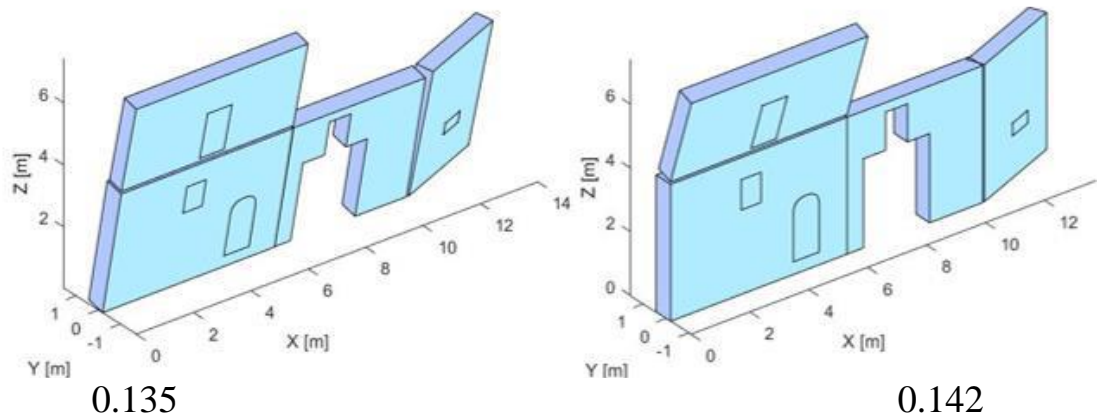

Figure 9. Walls D2-4, local failure mechanisms and horizontal load multipliers $\alpha_{0}$. 

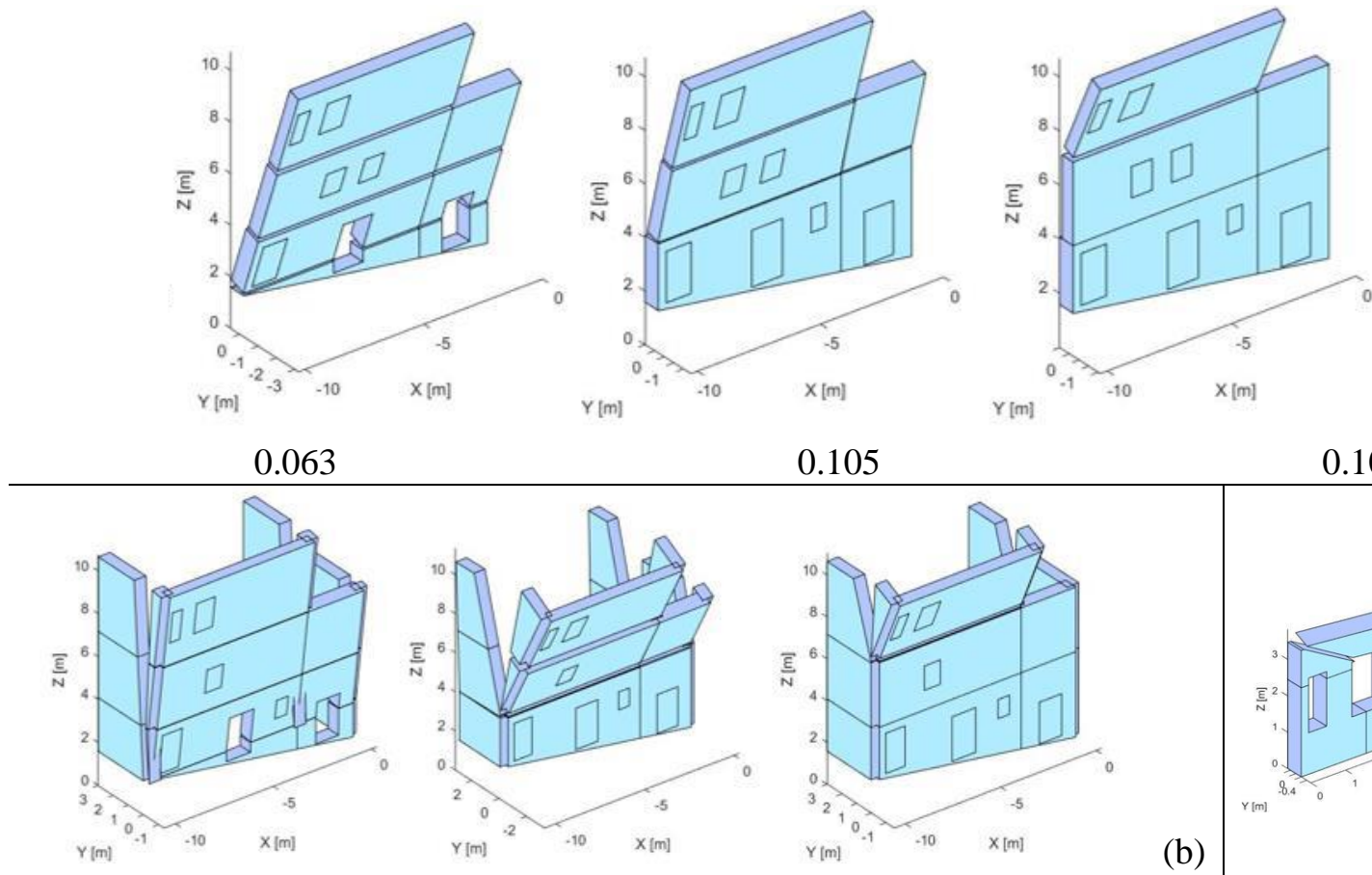

0.105

(a)

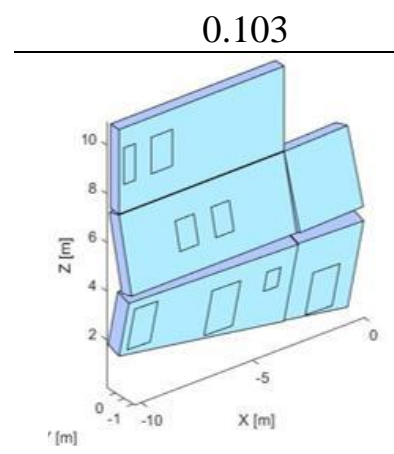

0.849
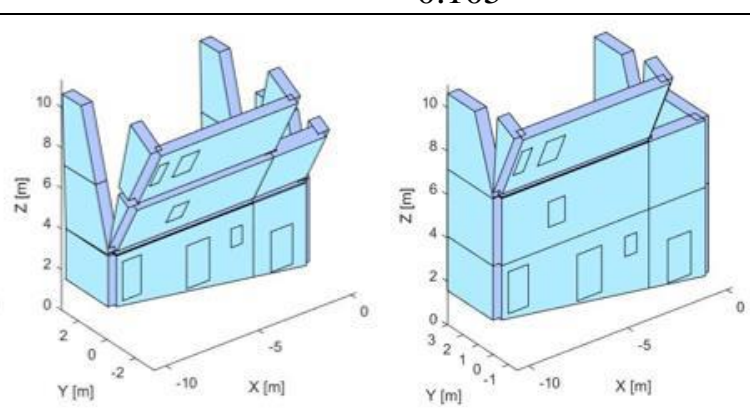

0.201

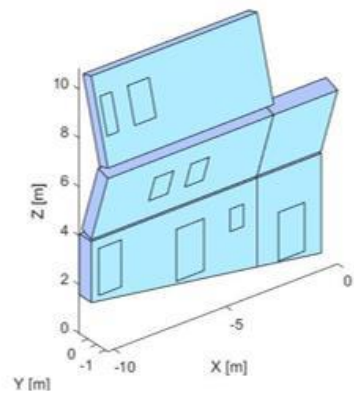

0.289

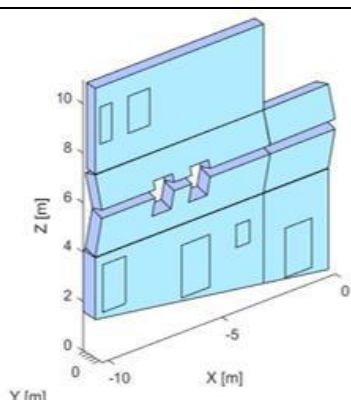

2.705 (b)

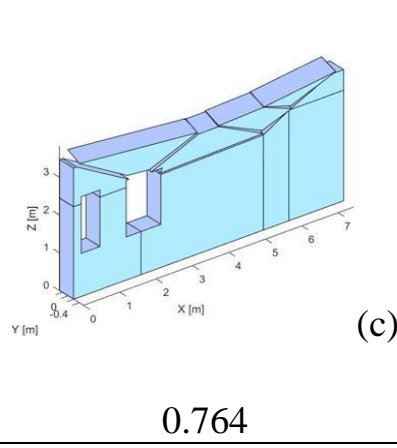

Figure 10. Wall D1, local failure mechanisms and horizontal load multipliers $\alpha_{0}$ : overturning with (a) low and (b) good quality of connection with orthogonal walls, (c) vertical flexure and (d) horizontal flexure at the top.
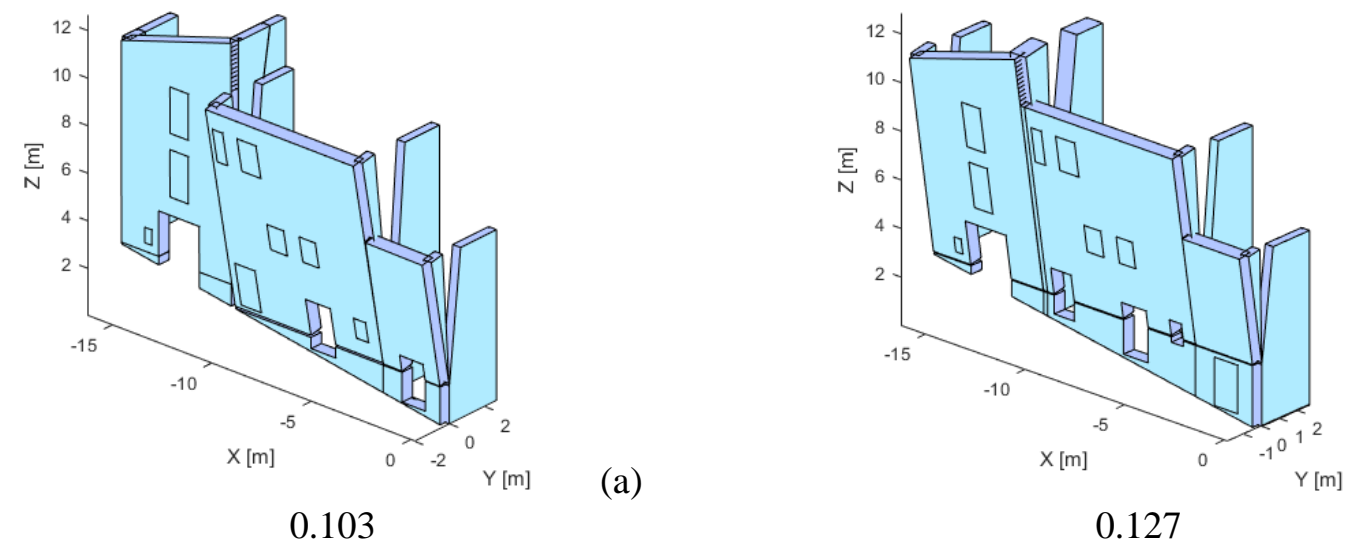

(b)

Figure 11. Walls $\mathrm{C} 1$ and D1, local failure mechanisms and horizontal load multipliers $\alpha_{0}$ with different hypotheses for the boundary wall between units C and D: (a) multi-leaf wall and (b) compact wall. 


\section{CONCLUSIONS}

A new computational tool for the automated seismic assessment of local failure mechanisms in masonry aggregates has been presented. This procedure relies on a NURBS-based upper-bound limit analysis and a meta-heuristic algorithm for the optimization of the kinematic load multiplier. The use of NURBS surfaces, which are very common on commercial CAD packages, allows an accurate representation of complex geometries and makes the tool easily interfaced with the CAD environment. The main characteristics of masonry material are taken into account by means of homogenization techniques. The analysis of the aggregate "Il Torrione" in the historical center of Arsita (Teramo) has been presented as first result about this work. A very fast evaluation of the most critical failure mechanisms of the aggregate is provided. Moreover, the proposed tool allows to take into account different conditions typical of masonry aggregates, such as low or good quality of connections between walls and presence of multi-leaf walls.

\section{REFERENCES}

[1] S. Giovinazzi, A. Balbi, S. Lagomarsino, A vulnerability method for buildings into historical centres (in Italian), in: Proceedings of the $11^{\text {th }}$ Italian Congress “L'Ingegneria Sismica in Italia”, Genoa, 2004.

[2] NTC2018. D.M. 17/01/2018 Aggiornamento delle «Norme tecniche per le costruzioni». S.O. alla G.U. n. 42 del 20/02/2018; 2018., (n.d.).

[3] Circolare del Ministero dei Lavori Pubblici "n. 617 del 2/2/2009 (2009) Istruzioni per l'applicazione delle "Nuove norme tecniche per le costruzioni" di cui al DM 14 gennaio 2008.", (n.d.).

[4] L. Rovero, V. Alecci, J. Mechelli, U. Tonietti, M. De Stefano, Masonry walls with irregular texture of L'Aquila (Italy) seismic area: validation of a method for the evaluation of masonry quality, Materials and Structures, 49 , 2297-2314, 2006. doi:10.1617/s11527-015-0650-2.

[5] A. Formisano, R. Landolfo, F.M. Mazzolani, G. Florio, A quick methodology for seismic vulnerability assessment of historical masonry aggregates, Proceedings of the COST Action C26 Final Conference "Urban Habitat Constructions under Catastrophic Events, 2014. doi:10.13140/2.1.1706.3686.

[6] A. Formisano, G. Florio, R. Landolfo, F.M. Mazzolani, Numerical calibration of an easy method for seismic behaviour assessment on large scale of masonry building aggregates, Advanced in Engineering Software, 80, 116-138, 2015. doi:10.1016/j.advengsoft.2014.09.013.

[7] R. Maio, R. Vicente, A. Formisano, H. Varum, hybrid and indirect assessment techniques, Bullettin of Earthquake Engineering, 2995-3014, 2015. doi:10.1007/s10518-015-9747-9.

[8] M. Valente, G. Milani, Damage assessment and partial failure mechanisms activation of historical masonry churches under seismic actions: Three case studies in Mantua, $\begin{array}{lllll}\text { Engineering } & \text { Failure } & \text { Analysis, } & \text { 92, 495-519, }\end{array}$ doi:10.1016/j.engfailanal.2018.06.017.

[9] M. Valente, G. Milani, Seismic response and damage patterns of masonry churches: 
seven case studies in Ferrara, Italy, Engineering Structures, 177, 809-835, 2018. doi:10.1016/j.engstruct.2018.08.071.

[10] M. Valente, G. Milani, Damage survey, simplified assessment, and advanced seismic analyses of two masonry churches after the 2012 Emilia earthquake, International Journal of Architectural Heritage, 2018. In Press. doi:10.1080/15583058.2018.1492646.

[11] M. Valente, G. Milani, Damage assessment and collapse investigation of three historical masonry palaces under seismic actions, Engineering Failure Analysis, 98, 10-37, 2019. doi:10.1016/j.engfailanal.2019.01.066.

[12] M. Valente, G. Milani, Earthquake-induced damage assessment and partial failure mechanisms of an Italian Medieval castle, Engineering Failure Analysis, 99, 292-309, 2019. doi: 10.1016/j.engfailanal.2019.02.008.

[13] M. Como, Statics of historic masonry constructions, Berlin Heidelberg, 2013.

[14] P. Roca, M. Cervera, G. Gariup, L. Pelà, Structural analysis of masonry historical constructions. Classical and advanced approaches, Archives of Computational Methods in Engineering, 17, 299-325, 2010. doi:10.1007/s11831-010-9046-1.

[15] J. Heyman, The stone skeleton, International Journal of Solids and Structures, 2, 249256, 1966.

[16] G. Milani, P.B. Lourenço, A. Tralli, Homogenized Approach for the Limit Analysis of Out-of-Plane Loaded Masonry Walls, Journal of Structural Engineering, 132, 16501663, 2006. doi:10.1061/(ASCE)0733-9445(2006)132:10(1650).

[17] G. Milani, P.B. Lourenço, A. Tralli, Homogenised limit analysis of masonry walls, Part I: Failure surface, Computers \& Structures, 84, 166-180, 2006. doi:10.1016/j.compstruc.2005.09.004.

[18] G. Milani, A. Taliercio, In-plane failure surfaces for masonry with joints of finite thickness estimated by a Method of Cells-type approach, Computers \& Structures, 150, 34-51, 2015. doi:10.1016/j.compstruc.2014.12.007.

[19] G. Milani, A. Taliercio, Limit analysis of transversally loaded masonry walls using an innovative macroscopic strength criterion, International Journal of Solids and Structures, 81, 274-293, 2016. doi:10.1016/j.ijsolstr.2015.12.004.

[20] A. Chiozzi, G. Milani, A. Tralli, A Genetic Algorithm NURBS-based new approach for fast kinematic limit analysis of masonry vaults, Computers \& Structures, 182, 187-204, 2017. doi:10.1016/j.compstruc.2016.11.003.

[21] L. Piegl, W. Tiller, The NURBS Book, Springer, Berlin, 1995. doi:10.1007/978-3-64259223-2.

[22] A. Chiozzi, M. Malagù, A. Tralli, A. Cazzani, ArchNURBS: NURBS-Based Tool for the Structural Safety Assessment of Masonry Arches in MATLAB, Journal of Computing in Civil Engineering, 30 \#401501, 1-11, 2016. doi:10.1061/(ASCE)CP.1943-5487.0000481.

[23] A. Chiozzi, G. Milani, N. Grillanda, A. Tralli, An adaptive procedure for the limit analysis of FRP reinforced masonry vaults and applications, American Journal of Engineering and Applied Sciences, 9, 735-745, 2016. doi:10.3844/ajeassp.2016.735.745. 
[24] A. Chiozzi, G. Milani, N. Grillanda, A. Tralli, A fast and general upper-bound limit analysis approach for out-of-plane loaded masonry walls, Meccanica, 53, 1875-1898, 2018. doi:10.1007/s11012-017-0637-x.

[25] A. Chiozzi, N. Grillanda, G. Milani, A. Tralli, UB-ALMANAC: An adaptive limit analysis NURBS-based program for the automatic assessment of partial failure mechanisms in masonry churches, Engineering Failure Analysis, 85, 201-220, 2018. doi:10.1016/j.engfailanal.2017.11.013.

[26] A. Chiozzi, G. Milani, N. Grillanda, A. Tralli, Fast and reliable limit analysis approach for the structural assessment of FRP-reinforced masonry arches, Key Engineering Materials, 747, 196-203, 2017. doi:10.4028/www.scientific.net/KEM.747.196.

[27] A. Chiozzi, N. Grillanda, G. Milani, A. Tralli, Vulnerability assessment of masonry churches through an automated fast limit analysis approach, Proceedings of the $23^{\text {rd }}$ Conference of the Italian Association of Theoretical and Applied Mechanics (AIMETA 2017), 2017.

[28] N. Grillanda, F. Manconi, F. Stochino, A. Cazzani, F. Bondi, A. Chiozzi, A. Tralli, On the analysis of the stellar vault of Santa Maria del Monte in Cagliari, $13^{\text {th }}$ International Conference of Computational Methods in Sciences and Engineering (ICCMSE 2017), Thessaloniki, Greece, 2017. doi:10.1063/1.5012365.

[29] N. Grillanda, A. Chiozzi, F. Bondi, A. Tralli, F. Manconi, F. Stochino, A. Cazzani, Numerical insights on the structural assessment of historical masonry stellar vaults: the case of Santa Maria del Monte in Cagliari, Accepted by Continuum Mechanics and Thermodynamics, 2019. doi:10.1007/s00161-019-00752-8.

[30] N. Grillanda, A. Chiozzi, G. Milani, A. Tralli, Collapse behavior of masonry domes under seismic loads: an adaptive NURBS kinematic limit analysis approach, Submitted, 2019.

[31] A. Formisano, G. Florio, R. Fonti, E. Candigliota, F. Immordino, A. Marzo, L. Moretti, M. Indirli, D. Abate, G. Furini, S. Pierattini, A. Screpanti, M. Angelini, T. Gambatesa, C. Massaia, Seismic vulnerability of historic centres: identification of damage mechanisms occurred in Arsita (TE) after L'Aquila earthquake, $15^{\text {th }}$ World Conference on Earthquake Engineering (WCEE 2012), 2012: pp. 24-28.

[32] R. Chiarini, M. Indirli, Piano di ricostruzione del comune di Arsita (Te) a seguito dell'evento sismico del 6/04/2009, 2013.

[33] M. Indirli, S. Bruni, F. Geremei, G. Marghella, A. Marzo, L. Moretti, A. Formisano, C. Castaldo, L. Esposito, G. Florio, R. Fonti, E. Spacone, S. Biondi, E. Miccadei, I. Vanzi, A. Tralli, C. Vaccaro, T. Gambatesa, The reconstruction plan of the town of Arsita after the 2009 Abruzzo (Italy) seismic event, $9^{\text {th }}$ International Conference on Structural Analysis of Historical Constructions (SAHC 2014), 2014: pp. 14-17.

[34] R. McNeel, Rhinoceros: Nurbs Modeling for Windows, Robert McNeel \& Associates, Seattle, 2008.

[35] P.R. Kennicott, Initial Graphics Exchange Specification, IGES 5.3, U.S. Product Data Association, 1966. https://books.google.com/books?id=FHPhGwAACAAJ\&pgis=1. 